\title{
PARAMEDIKAL KONULAR
}

\section{CUMHURIYYET DO̊NEMİ (1928-1994) TIP DERGILERIMMIZINN KISALTILMIŞ İSIMM İNDEKSİ VE ANALİZI}

\author{
ANALYSIS AND ABBREVIATED LIST OF MEDICAL JOURNALS \\ PUBLISHED IN TURKEY BETWEEN 1928-1994
}

Ragip KAYAR

\section{SUMMARY}

443 medical journals have been published in Turkey between the years 1928 and 1994192 of them in the last 20 , and 144 in the last 10 years. The number of journals that are still being published currently are 57 and 40 of these respectively (30 and 28 percent). The number of journals being published at present is 187 . Of the 26 journals published in foreign language, only 13 have remained in publication.

Only 71 out of 299 journals $(23.7 \%$ ) are beeing published for more than 10 years.

This uncontrollable increase in journal numbers seems to be a major negative impact on the scientific level and on the regularity of the journals.

It is a major opinion that selected journals should be supported on funds that will tightly be controlled by a board of editors, who at the same time will judge on the quality of the relevant journals.

(Keywords: Medical Publishing)

\section{ÖZET}

Son 65 yılda ülkemizde 443 Tıp Dergisi yayınlanmıştır. Bunların 192'si (\%43) 20 yılda (1974$94) 144$ 'ü (\%33) ise son 10 yılda (1984-94) yayınlanmaya başlamıştır. Bunların yalnızca 57 ve 40'1 (\%30 ve \%28) i yayınlanmaya devam etmektedir. Şu anda yayınlanmakta olan tüm dergilerin sayısı ise $187^{\prime}$ dir. Yabancı dilde çıkarılan 26 dergiden 13'ü (\%50) yayınlanmaya devam etmektedir.

299 dergiden 10 yilı aşan yalnızca 71 dergi (\%23.7) bulunmaktadır.

Dergi sayılarındaki bu kontrolsüz artışın bilimsel düzey ve yayın sürekliliğini olumsuz etkilediği anlaşilmaktadir.

Bilimsel düzeyi ve sürekliliği arttırmak için oluşturacak bir editörler komisyonun seçeceği dergilerin desteklenmesi gerektiği düşünülmektedir.

(Anahtar Sözcükler: Tibbi Yayıncılık)

Yazışma: SSK Tepecik Hastn. I. Genel Cerrahi Kliniği 
Tip dergilerimize ait ilk liste 1945 'te Kızıldağlı (1) tarafından bildirilmiş, bunu 1961'de Özbek (2) ve Şehsuvaroğlu (3) izlemiştir. Bu raporları 1973 ve 1975 'de yine Şehsuvaroğlu izlemiş (4,5), 1981'de Kazancıgil ve Solok (6) önceki çalışmalara önemli ekler yapmışlardir. 1990'da Kartoğlu ve Hoşgeçin, aynı yıl Hayran ve Kayhan sadece çıkmakta olan dergileri bildirmişlerdir $(7,8)$. Konuya ait son incelemeyi ise 1991'de Özsoylu sunmuştur (9). Ayrica Taşkiran ve Kazacigil'in bibliyografyalarından $(10,11)$ yararlanılmıştır.

Bu çalışmanın amacı yerli tıp dergilerimizin toplu alfabetik indeksini oluşturmaktır. $\mathrm{Bu}$ amaçla Latin alfabesine geçilen 1928 yılı başlangıç olarak alınmış ve yayınlanmış dergi listeleri temel alınmıştır.

Ayrica dergileri yayınlanmaya başlamaya ve sonverme tarihleri ile sürekli olanlarin son volüm ve sayı numaraları saptanmıştır. Böylece kronolojik düzendeki sayısal değişikliklerini de analiz etme olanağ 1 sağlanmiştir.

\section{GEREÇ VE YÖNTEM}

Latin alfabesine geçilen 1928 yilından 1.8.1994 tarihine kadar İzmir'de bulunan 4 ayrı kütüphanede (Milli Kütüphane, Ege T1p Fakültesi, 9 Eylül Tip Fakültesi ve SSK Tepecik Hastanesi Kütüphaneleri) bulunan yerli Tip dergileri incelendi.

Ayrica daha önceki araştiriciların saptadığ1 dergi listeleri rehber olarak alındı.

Dergilerin yayına başlayış tarihi, kapanmışsa son yayınlandı̆̆1 y1l kaydedildi (Örn. Aegan Med J 1972-83). Yayınlanmasi süren dergilerin ise kalın (bold) harflerle kütüphanelere ulaşmış son sayısında bildirilen volum ve sayısı [örn.Ağrı 1989: 6(2)] kaydedildi. Burada volüm (cilt): 6 say1 2 'dir.

Bu arada bazı dergilerde yıl ve volüm ilişkisinin bozulduğu dikkati çekti. Bazı dergilerin yılda birden fazla volüm numarası kullandıkları, bazılarinsa geçen yılların sayısindan daha az volüm sayısına ulaştıkları belirlendi. Bunun volüm sayısinı her yil otomatikman arttırmanin "unutulduğu" ya da yayına birkaç yıl ara verilmesinden kaynaklandığı anlaşıld1.
Buradaki incelemeye Dişçilik, Eczacllik, Veteriner, Hekimlik ve Hemşirelik bilimine ait dergiler alınmamıştır. Ayrıca Tıbbi magazin, duyuru bültenleri, Tabib odası dergileri gibi malzemeye yer verilmedi.

1928'den eski dergiler arap harfleri ve eski türkçe basılması nedeniyle inceleyemediğimizden çalışma dişında birakılmıştır. Bunun tek istisnasi 1925 te "Tedavi Noktaları" adıyla basılmaya başlayan ve 1935 'ten itibaren "Dirim" adını alan ve halen yayınlanmakta olan en uzun ömürlü tıp dergisidir.

Bazı dergiler birkaç kez isim değiştirmişler ve uzunca süre ara vermişlerdir. Bu tip dergilerin en son isimleri başlık yapılmış, eski isimleri alt başlık halinde yeniden eskiye doğru bildirilmiştir. (Örnek: Dicle Trp Derg). Okuyucunun aradığı dergiyi kolay bulması için eski ve yeni isimler alfabetik dizinde ayrı ayrı verilerek birbirine göndermeler (bk: bakınız) yapılmıştır.

Dergiler alfabetik siraya göre listelenmiştir.

Kisaltmalarda içinde yabancı kelime bulunan dergiler için "İndex Medicus" kuralları uygulanmiştır.

Sik Kullanılan bazı Türkçe Kelimelerin kisaltmaları Tablo 1' dedir.

TABLO 1: Listede kullanılan kisaltmalar

\begin{tabular}{llll}
\hline Bakınız & Bk & Hastanesi & Hstn \\
Bilimleri & Bil & Kliniği & Kli \\
Bulletin & Bull & Klinikleri & Klin \\
Bülteni & Bült & Mecmuası & Mec \\
Cerrahi & Cer & Merkezi & Merk \\
Cemiyeț & Cem & Oncologica & Oncol \\
Çocuk & Çoc & Orthopedica & Orthop \\
Dergisi & Derg & Reproductiva & Reprod \\
Devlet & Dev & Sağlığı & Sağl \\
Dispanseri & Disp & Turcica & Turc \\
Fakültesi & Fak & Turkish & Tur \\
Hastalıkları & Hstl & Üniversitesi & Üniv \\
\hline
\end{tabular}

Bu arada 13 derginin yayına başlama tarihi belirlenememiştir. Kapandiğ1 y1l saptanamayan dergi sayısı 121'dir. Böylece 134 
derginin başlangıç ve kapanma tarihleri bilinmemektedir. Çünkü dergilerin kapandiğı yuli kesin bildiren bir kaynak bulamadik. Listede yayina ara vermiş veya sona ermişolduğu düşünülen dergiler normal, ince harfle verilmiştir. Düşünülen demekten kastımız: herhangi bir dergi çıkmakta olmasına rağmen inceleme yaptı̆̆ımız 4 kütüphaneye ulaşmamış olabilir.

İzmir Milli Kütüphanesindeki incelememizde tıp dergilerinin "Dergiler" bölümünde diğer konudaki dergilerle birlikte smif landırıdiğ1 görülmüştür. Bu durum araştırıcıyı tıp dergilerini bulmak için binlerce dergi arasinda tarama yapma zorunda birakmaktadir.

Fakülte Kütüphanelerinde ise Trp dergilerimizin tasnif ve kayıtlarında birtakım eksiklikler gözlenmiştir.

Bütün bu problemlerin başlica nedeni dergilerimizin düzenli çıkarılmayışı ve profesyonel dağıtım sistemiyle her kütüphaneye ulaştırılamayışıdır.

Dergilerin yarıdan çoğu İstanbul'da çıkarilmış bulunduğundan, sadece İstanbul dişındaki dergilerin hangi dernek veya $\mathrm{ku}-$ ruluşca çıkarıldığı dergi adının sonuna parantez içinde eklenmiştir. Örneğin: Arşiv (Çu-kurova) $1992 ; 2$ (4).

\section{SONUÇ VE BULGULAR}

1928-1.8.1994 tarihleri arasında İzmir'de mevcut 4 tıp kütüphanesine ulaşmış tüm dergiler ve kütüphane kayıtları incelenmek suretiyle 443 derginin yayinlandiğı, bunlarin 183'ünün halen ç1kmakta olduğu saptanmiştır.

Son 10 yılda (1984-93) 144, son 5 yilda ise (1989-93) 86 yeni derginin yaym hayatına. girdiği saptandi (Tablo2).

10 yil öncesinde çıkmaya başlamış 290 dergi arasindan yalnizca 71 derginin 10 yilı (\%24.5), 48 derginin 20 y1li (\%16.6), 30 derginin 25 yili (\%10.3), 20 derginin 30 y1lı (\%) ), 8 derginin 40 yilı (\%2.8) ve yalnıca 4 derginin 50 yilı (\%1.4) aşkın bir süredir yayınlanmakta olduğu belirlendi.

443 dergiden 26's yabanc1 dilde yayınlanmıştır (\%5.9). Bunlardan 13'ünün (\%50) yayını sürdürebildiği ve 12 'sinin ise son 5
Tablo 2 : Ülkemizde son 10 yilda çıkan ve yayını süren dergi sayısı

\begin{tabular}{lclllll}
\hline \multicolumn{3}{c}{ Dergi SayıSı } & \multicolumn{5}{c}{ Dergi SayıSı } \\
YII & Çıkan & Süren & Y II & Çıkan & Süren \\
\hline 1983 & 5 & 3 & 1989 & 15 & 7 \\
1984 & 8 & 2 & 1990 & 20 & 5 \\
1985 & 9 & 1 & 1991 & 16 & 3 \\
1986 & 12 & 5 & 1992 & 16 & 1 \\
1987 & 18 & 6 & 1993 & 19 & - \\
1988 & 11 & 7 & 1994 & 9 & - \\
\hline
\end{tabular}

yılda çıkarılmaya başladiğı saptand1.

1974 - 83 yılları arasinda çıkmaya başlayan 48 dergiden halen sadece 17'si (\%35.4) çikmaya devam etmektedir (Tablo 2). 198493 yilları arasinda yayınlanmaya başliyan 144 dergiden ise sadece $40^{\prime} 1(\% 27.8)$ yayın sürdürebelmiştir.

\section{TARTISMA}

Ülkemizde yayinlanan tip dergileri daha önce çeşitli araştıricılar tarafindan topluca değerlendirilmiştir (Tablo-3).

Bu tabloyu incelerken iki noktay1 vurgulamak gerekir:

a) Incelenen dönem: Çoğu çalışmalarda Cumhuriyet döneminin başlangıc1 (1923) esas alınirken, bazı çalışmalarda olduğu gibi (6) çalışmamızda Latince alfabeye geçiş yılı (1928) esas alinmıştir. Böylece 1945 'te 43 olan toplam dergi say1si, 1961'de iki ayrı çalışmada 104 ve 123 olarak bildirilmiş, 1973'te 231'e 1994'te ise 443'e yükselmiştir. Son 20 yilda yayın hayatına giren dergi say1sı \%91.8 artmiştır.

b) Incelemede yanlizca tıp dergileri alınmıştır. Önceki çalışmalarda buna uyulmadığ1 görülmektedir (Tablo 3).

Liste ve tablolarda verilen bu rakamlar kapanan ve süren tüm dergilerin toplam sayısıni temsil etmekte ve Tıp dişı alanlardaki (Eczacılik, Dişçilik, Veteriner Hekimlik ve Hemşirelik) dergileri içine almamaktadır.

Yaymlanmaya devam eden dergi sayıs incelendiğinde 1961 'de 45, 1973'te 82 iken. 1990 'da 63 ve 72 olarak saptanmiştır. 1961' deki yüksek rakamin tıp dişı dergileri kapsamış olma olasilığı yüksektir. 1990'da iki ayrı çalışmada birbirine yakin rakamelde 
TABLO 3: Ülkemizdeki Tıp DergileriniToplu Değerlendiren Çalışmalar

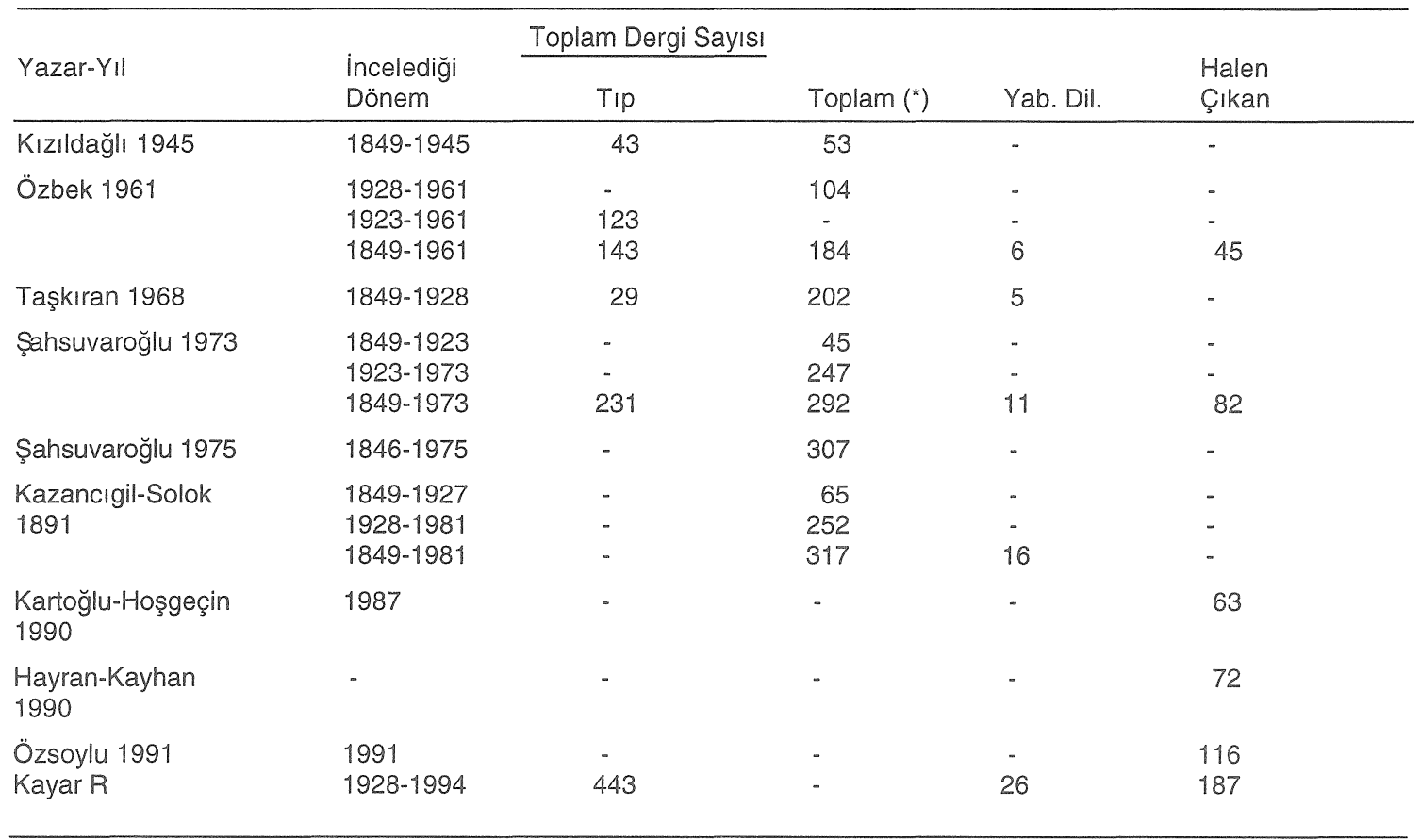

edilmişse de 1991'de 116 derginin aktif yayın yaptığı bildirilmiştir (9). 1991-94 döneminde yeni 60 dergi çıkarıldiğı hesaba katilırsa (Tablo 2) bu rakam saptanirken sadece 7 derginin atlanmiş olduğu söylenebilir.

Buradaki çalışmada kullanılan sayı kısıtlayıcı kriterlere (Başlangıç döneminin 1923 y1l1 yerine 1928'in alınmas1, Tip dişındaki alan dergilerinin eliminasyonu) rağmen önceki bildirilen rakamların çok üstünde bir rakam elde edilmiş olması, çalışmanın titizlik derecesinin ve kapsamınin gerçeğe yakınlığını telkin etmektedir.

Çalışmamızda 1974-83 arasındaki 10 y1lda yayın hayatına başlayan 48 dergiden 17 'sinin (\%35.4), 1984-93 arasindaki 10 y1lda ise 144 dergiden 40 'inin (\%27.8) yaymini sürdürebildiği saptanmıştır (Tablo 2).

Bu değerler son iki 10 yilda yeni çıkan dergi sayıları birbirleri ile kıyaslandığında (48'e karşılık 144) (\%200) civarında bir artış1 yansıtmaktadır. Bu artış dergilerin yayını sürdürme oranlarında görülmektedir. Bir başka deyimle son 10 ve 20 yılda çıkarilmaya başlıyan dergilerden en az \%75'i kapanmakta ve yayın yaşamını sonlandırmaktadir.

Nitekim 10 yil öncesine kadar yayınlanmış 299 dergiden yalnızca. 71'i (\%23.7) 10 yılı aşabilmiştir. Bu rakamlar dergi çıkarma girişimlerinin geçmişte olduğundan çok daha yüksek bir sayıda günümüzde adeta bir patlama tarzında ortaya çıktığını, ancak yayunlanmaya başliyan dergilerin 3/4'ünün 10 yila erişmeden (çoğunun birkaç yılda) kapandığını göstermektedir.

Kapanan dergilerin yarısı ilk 5 yıl içinde kapanmıştır (Tablo 4). Ancak 10 y1l1 aşmasına rağmen yayını sürdüremeyen dergilerin bütüne oranı (\%46.5) küçümsenmeyecek düzeydedir.

Bütün bu veriler yeni dergi sayısmin anormal artışının, dergilerin 3/4' ünün yayınlarinı sürdüremeyişine yolaçmış olabileceğini düşündürmektedir. Aşırı sayıda 
TABLO 4: Kapanan Dergilerin Yayın Süresi

\begin{tabular}{cc} 
Süre $(Y I I)$ & $\frac{\text { Dergi SayıSI }}{10}$ \\
\cline { 2 - 2 } $1-2$ & 25 \\
$3-5$ & 13 \\
$6-9$ & 22 \\
$10-19$ & 11 \\
$>20$ & 71 \\
TOPLAM &
\end{tabular}

dergi çıkarılmasının yarattı̆̆ı muhtemel sorunlar ise şunlardir:

1- Dergilerin 3/4'ünün kapanışı ve bu dergilerin arşivlerde düzenli saklanmadiğ1 birlikte değerlendirildiğinde büyük bir kayıp ortaya çıkmaktadır. Ayrıca kalıcı eser niteliğine girmeyen bu geçici dergilerde yeralan çalışmalar için gerek sarfedilen emekler gerek basım için sarfedilen paralar boşa gitmiş olmaktadir.

2- Dergi sayısının çoğalması yazarın çalışmasını kolay yayınlama olanağı vermekte ve bu dergi başına düşen başvuru sayısını azaltmaktadir. Başvurularin azalması editörlerin bilimsel düzeyden taviz vermedikleni takdirde dergiyi düzenli çıkaramamalarina yol açabilmektedir. Bu da bilimsel denetimin gevşemesi ve yazıların bilimsel düzeyinin düşmesi anlamina gelir.

3- Çok sayıda dergiye dağılmış çalışmalar içindeki belirli bir alanın herhangi bir araştırıcı için (yerli tıp indeksi de bulunmadiğına göre) tam taranması olanaksızdir. Araştıricıların konularını izlemeleri güçleşecek ve rekabet ile gelişmenin tetiği olan bilimsel iletişim azalacaktir.

4- Adayın yerli çalışmalarını değerlendirirken, herhangi bir jüri üyesi için yeni bir dergide yayınlanmış bir çalışmanın gerekli asgari bilimsel denetimden geçip geçmediği kuşkusu her zaman için vardir. Dergilerin sayıca çok artışı bu kuşkuları artırmaya yolaçacaktır.

Bütün bu sakıncalar karşısında, demokratik bir ülkede dergi sayılarını kısıtlamak veya yeni dergi basılmasinı engellemek de söz konusu olamiyacağına göre şu önlemlerin süratle alınması gerektiğine inaniyoruz:
1- Konuya duyarli ve yetkin dergi editörleri bir komisyon oluşturmalıdir.

2- Editörler Komisyonu çıkmakta olan bütün dergileri uluslararası bilimsel yayın prensipleri ve bilime katkı düzeyi bakımindan iki ayrı katergoride değerlendirmeli ve yeterli bulunan dergilerin isimleri 3 veya. 6 aylik bültenler halinde tıp bilimi eğitimci ve yöneticilerine düzenli olarak ulaştırilmalidir.

3- Yeterli bulunan dergilerin listesi PTT'nin indirimli posta tarifesine tabi olmasi için yasal girişimler ve sonuçlar sağlanmalıdir.

\section{YAZARIN NOTU:}

Bu çalışmada sunulan bilgiler arasinda kontrolden kaçan eksik ve yalnışliklardan dolayı okur ve dergi editörlerinden peşinen özür dilerim. Art niyetin söz konusu olamiyacağı bu çalışmada düzeltilmesi veya eklenmesi gereken bilgiler edinirsem ek bir düzeltme listesi halinde yaymlamak isterim. Konuya duyarlı okur ve editörlerin ikaz ve katkilarını dört gözle bekliyorum.

\section{KAYNAKLAR}

1- Kızıldağlı S. Türkiye'de Tip mecmuaları hakkında. Dirim $1945 ; 20$ (3-4) : 71-8.

2- Özbek FK. Süreli Yaymlar. Dirim 1961; 36 (3-4) : 133-9.

3- Şehsuvaroğlu BN. Basın tarihimize sihhi mevkuteler. Yeni Tip Alemi 1961 ; 10 (Temmuz-Aralik) : 484-501.

4- Şehsuvaroğlu BN. Türkiye'de sağlıkla ilgili olarak yayınlanan periyodikler. İstanbul Top Fak. Mec. 1973 ; 36 : 169-98.

5- Şehsuvaroğlu BN. Tibbi ve sihhi periyodiklerimiz arasinda Dirim'in yeri ve önemi Dirim $1975 ; 50(9)$ : 38794.

6- Kazancıgil A, Solok V. Türk Tip Dergileri ve süreli yaymlan ïzerine analitik bir inceleme (1844-1981) Cerrahpaşa Tıp Fak Derg. 1981 ; 12 : 373-82.

7- Kartoğlu Ü, Hoşgeçin K. Sağlık ve Toplum. 1990 ; (3) : $38-40$.

8- Hayran O-Kayhan M. Yerli ve Yabancı Tip Dergileri. Sağlık ve Toplum. $1990 ;(54): 61-3$.

9- Özsoylu Ş. Türkiye'de Tip Dergileri. Tip Alaninda Bilimsel Yazılar Simpozyumu. 30.9.91 TÜBITAK Ankara $1992: 67-70$.

10- Taşkıran N. Cerrahi Makaleler Bibliyografyası (1849-1966) Istanbul Son Telgraf Matb. 1968, 565 sayfa.

11-Kazancrgil A. Türk Jinekoloji ve Obstetrik Bibliyografyası (1923-1973) Istanbul Kağıt ve Basım Işl. AŞ 1973, 326 sayfa. 